Ausführung der Reststickstoffbestimmung.

Abmessen und EntciweiBendes Serums. In ein zylindrisches, nicht zu enges Zentrifugenrohr wird mittels einer genaucn Pipettc 1 con Serum eingebracht. Hierzu gibt man aus einer Büretle $7 \mathrm{ccm}$ destillierten Wassers und hicrauf mittels einer Pipette $2 \mathrm{ccm}$ Plosphorwolframsäure. (Dic Pliosphorwolframsaurc wird hergestellt, indem man $5 \mathrm{~g}$ wolframsaures Natrium in $100 \mathrm{cem}$ destillierten Wassers löst und zu dieser Lösung sodann $10 \mathrm{ccm}$ eincr 25\% igen Phosphorsäurc zusetzt.) Hicrauf wird einige Minuten scharf zentrifugiert. Dic uberstehende Lösung wird durch ein kleines Filtcrchen in ein Reagenzrohr gegossen und dann $5 \mathrm{cem}$ des klaren Filtrates, entsprechend cinem halben cem Scrum, verbrannt. Falls einc Zentrifuge nicht zur Verfugung steht, kann auch nach cinigem Stehen bequem vom Eiwcißniederschlag abfiltriert werden.

Det Dampfschlucker. Dicser einfache Glasapparat ermöglicht es kleinen Krankcnhäıscrn und praktischen Aerzten, denen ein kostspieliger und platzraubender Abzug nicht zur Verfügung steht, die bei der Kjeldahl-Verbrennung auftretenden unerträglichen Schwefelsäureverbrcnnungsdämpfe ohne jede Belästigung der Atmungsorganc 711 entfernen. In einem gewöhnlichen Kjeldahl-Kolben A ist ein einfach gebogenes Destillationsrohr von $30 \mathrm{~cm}$ Lïnge eingeschliffen, das in spitzem Winkcl in ein vertikalstchendes T-Stïck ausläuft (T). Vor dem Ucbergange in das T-Stück ist cin kleines Schwimmerventil (s) angebracht, kurz nach der Biegung hinter dem Kolben ein kleiner Hahn (h) angeschmolzen. Den oberen Teil des vertikalen T-Stückes verbindet min mit einem Schliach mit der Wasserleitung, vom unteren Teilc führt ein zweiter Schlauch in das Abflußbecken. Man lïßt einen hinreichend starken Strom Wasser durchfließen. Dic Verbrennung gestaltet sich in folgender einfachen Weise:

In den Kjeldahl-Kolben A

Aus dem Laboratorium der Innern Abteilung des Krankenhauses der Jüdischen Gemeinde in Berlin. (Direktor: Geh.-Rat Strauß.)

\section{Ueber Vereinfachungen des Kjeldahl-Verfahrens, insbesondere zur Bestimmung des Reststickstoffs.}

Von Dr. Arnold Hahn, Laboratoriumsleiter.

Das klassische Verfahren der Stickstoffbestimmung nach K jeld a hl bildet einen der Grundpfeiler der analytisch-physiologischen Chemic. Immerhin setzt es sich aber aus einer Rcihe von Operationen zusammen, die seine Ausbreitung auch in jenc ärztliche Kreise, denen die Hilfsmittel eines größeren Laboratoriums nicht zur Verfügung stehen, erschweren oder gar verhindern. Dies zeigt sich 11 il. in besonders störender Weise bei der Ausführung von Reststickstoffbestimmungen im Blutserum. Durch die vor nunmehr fast zwei Jahrzehnten erschienenen Untersuchungen von $\mathrm{H}$. Strauss, die die große Bedeltung von Reststickstoffbestimmungen für die Beurtcilung der Niercnfunktion dargetan haben, ist dic Untersuchung auf Reststickstoff Gemeingut der Aerzte geworden, sodaß zum mindesten für diesen Z Zweck eine bequene Ausfuhrung des Kjeldahl-Verfahrens besonders erwünscht ist. So sehen wir denn auch in den letzten Jahren das lebhafte Bestreben, durch Ausirbeitung von Mikrometloden die Ausführung der Reststickstoffbestimmung zu beschlcunigen und der Verwertung kleiner Substanzmengen anzupassen. Schon dic in den "Nephritiden" von H. Strauss angegebene Methode beschränkt sich auf die Verarbeitung von $2 \mathrm{ccm}$ Scrum. In letzter Zeit hat besonders $\mathrm{J}$. B ang ein gutes Mikroverfahren angegeben. Zur Ausführung des B a ng schen Verfahrens sind jedoch noch immer viele und zum Teil kostspielige Hilfsmittel nötig, dic auszuführenden Operationen sind ferner keineswegs einfach, sodaB sic fur weitere Acrztekrcise sehwer-
lich geeignet sind.

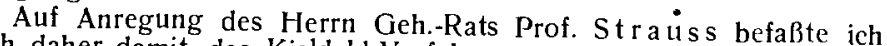
mich daher damit, das Kjeldahl-Verfahren so zu vercinfachen, ohne größere Hilfsmittel eines Chemischen zu vercinfachen, daß es ohnc Abzug, unter Erleichterung der auszufülirenden Operationen, in kurzer Zeit ausgeführt werden kann. Hicrbei licß ich mich von folgenden Gcsichtspunkten leiten:

1. Beschränkung der Hilfsmittel:

a) Beseitigung der bei der Verbrennung auftretenden ubclriechenen Dämpfe ohne Bcnützung cines Abzuges.

b) Ausführung der Destillation in cinfachster Form, ohne Benutzung von Kuhlvorrichtungen.

2. Erleichterung der auszufuhrenden Operationen :

a) Einfache Bestimmung der angewendeten Substanzmengc

b) Einfache und schnelle Enteiweißung.

c) Titration mit $n / 100$ Alkalien und Säurcn und tnit cinem Ind1-
kator, der sofort einen deutlichen Umschlag gibt. wird die enteiweißte Substanz
(siehe oben), cin Drittel Teelöffel Kaliumsulfat, einige Körnchen Kupfersulfat und $1 \mathrm{ccm}$ konz. Schwefelsäure eingebracht und hierauf das Destillationsrohr aufgesetzt. Man erhitzt mit freicr Flamme ohne Drahtnetz. Die zuerst entweichendenVerbrennungsgase und das Wasser werden restlos von dem fließenden Wasser verschluckt resp. desodoriert. So-

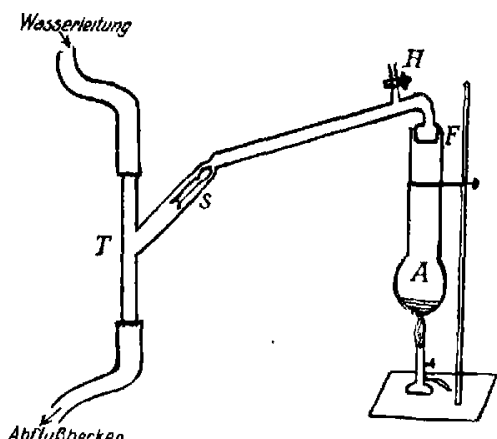

uberdestilliert ist, beginnt die

Schwefelsäure zu sicden, die

Dämpfe gehen jedoch nicht über,

da sie schon im oberen Teile des Kolbens kondensiert werden. Dadurch entsteht cin luftverdunnter Raum, das flicBende Wasser steigt in dis Destillationsrohr, hebt das Schwimmerventil und wird so am Uebertreten in den Kolben gehindert. Nun wird dic Verbrcnnung bis zıIr Vollendung (hellgrünc Färbung) fortgesctzt. Hierauf wird durch Oeffnen des Hahnes Luft in den Apparat eingelassen, der Schliff (F) aus den Kolben gezogen und nur lose daraufgelegt. In dieser Stcllung laßt man crkalten. Die Verbrennung beansprucht ctwa 5 Minuten. Der Apparat bedarf während der Verbrenunung keiner Aufsicht und ist für Kjeldahl-Bestimmungen jeder Art und naturlich auch für andere Operationen gecignet, bei denen ubelriechende, wasserlösliche Dämpfe auftreten (z. B. Eindampfen von Urin). Statt mit Schliff wird er atuch mit cinfachem Rohr hergestellt, das mittels Stopfens in jeden Kolben eingefiuhrt werden kani1 1). Wo ein Abzug vorhanden ist, uird die Verbrennung ohne Dampfschlucker in cinem gewölinlichen Kjeldahl-Kolben von $200 \mathrm{ccm}$ itusgeführt, der dann auch z.u der folgenden Destillation verwendet wird.

Die Destillation. Nachdem der Verbrennungskolben (A) auf etwa $60^{\circ} \mathrm{er}-$ kaltet ist, sctzt man sofort $10 \mathrm{ccm}$ Wasser hinzu. Die folgenden Operationen sind genau auszuführen, da nur so eine ruhige Destillation ohne StoBen verbürgt ist: Man kithlt den Kolben unter dem fließenden Wasser der Wasserlertung ab und gibt dann mittels einer Pipette $25 \mathrm{ccm}$ Alkohol (etwa $94 \%$ ) hinzu, indem man dabei gleichzeitig etwa an dem Halse noch haftende Schwefelsäure in den Kolben hineinspült. Nun stellt man den Kolben auf ein Drahtnetz. Als Vorlage

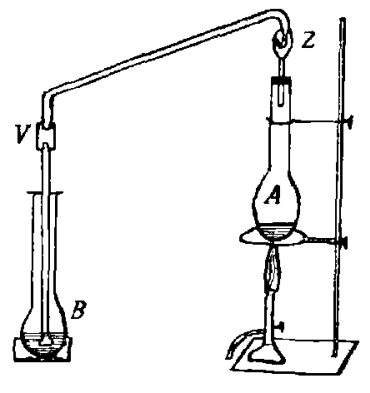

benützt man cinen zweiten Kjeldahl-Kolben (B) von etwa $200 \mathrm{ccm}$ Inhalt. In diesell miBt man $10 \mathrm{ccn1}$ n/100 Schwefelsäure. Das Rohr, das in
diesen Kolben cintaucht, soll nicht zu dick sein. An plattet man es ab, indem inan mit ciner Ticgelzange die Wandungen uber der Flamme zusanmendruckt. Es soll nur cinc ganz schniale Oeffnung vorhanden sein. Sobald der Apparat zusanumengestellt ist grießt mall in den Kolben A vorsichitig $5 \mathrm{com} 330 \%$ ioc Natronlat ist, und zwar so, daß dadurch die Flïssigkeit im Kolben ne Natronlauge, wird. Dies geschjeht am besten so der Innenwand des Kolbensten so, daß man die Natronlauge an Wcisc, daß die Stellen, albens hinablaufen läßt, natürlich aber in der benctzt werde Stellen, an die der Gummistopfen kommt, davon nicht benctzt werdeti. Hicrauf schließt man den Kolben. Der Aufsatz (Z) 
auf den Kolben ist der gewöhnliche bei Kjeldahl-Destillationen benutzte Sicherheitsaufsatz. Die Flüssigkeit im Kolben darf nach Zusatz der Natronlauge nicht umgeschuttelt werden. Man crhitzt sofort mit der vollen Flamme cines starken Brenners. Dic Einfachheit des Apparates 1st aus der Zeichnung ersichtlich 1). Eine Kühlung ist nicht nötig. I ic Destillation erfolgt in vier Phasen: Zuerst sicdet der Alkohol, verdichtet sich an den Wandungen der Rohre und gelangt als Flis suglieit in die Vorlage; sobald der Apparat die Sicdetenıpcratur des Alkohols angenommen hat, gelangt der Alkohol da $\mathrm{d}$ p f fö $\mathrm{rm}$ ig in die Vorlage; nach der Verdampfutig des Alkohols beginnt sich der Wasserdampt im Apparat -zu kondensieren, und man sieht nunmehr das flussige Wasser in die Vorlage übergehen. Als letzte Phase schlicBlich gelangt das Wasser als Dampt in die Vorlage. Nun beginut meistens der in dieser bercits kondensierte Alkohol zu kochen. Dies ist gunstig, da dadurch dic Flússigkeitsmenge verringert wird. Ein Ammoniakverlust tritt nicht cin. Etwa 1 Minute nach Auftreten des Wasserdampfes ist dic Destillation beendet. Man kocht zweckmá $\beta_{1 y}$ so lange, bis de Kochflussigkeit zu stoßen beginnt. Beinı Auftreten des ersten stärkeren Stoßes unterbricht man die Destillation, indem man die Gummiverbindung bei $V$ löst. Die ganze Destillation (sannt Zusammenstellen des Apparates) dauert etwa 6 Minuten. Das Rohr wird nun mit möglichst wenig Wasser außen und innen abgespritzt (das Gesamtvolumen der Flüssigkeit soll etwa $45 \mathrm{ccm}$ betragen) und der Kolben unter fließendem Wasser gekühlt.

Die Titration. Man titriert mit $n / 100$ Natronlauge. Eine genaue Titration mit $n / 100$ Lauge resp. Säure war bisher nur mit Hilfe der Jodometric möglich. Die Jodometrie ist ein sehr genaues Verfahren, aber sie verlangt mehr Maßflüssigkeiten als die Alkalımetric, und diese Maßflussigkciten sind keineswegs halthar und bedingeu deshalb eine Unsicherhcit der Resultate, die nur durch häufige Kontrollen behoben werden kann. N/100 Sauren und Alkalien sind dagegen leicht herzustellen und sehr gut halthar. Eine genaue Titration mit so schwachen Säuren war aber bisher nicht möglich, weil es an cinem geeigneten Indikator gebrach. Bei Verwcndung der bisher gebräuchlichen Indikatoren war ein scharfer Farbenumschlag nicht zu erreichen, da in der Nähc des Neutralisationspunktes die Farbell inmer wieder ineinander pendelten. Durch Zusammenstellung folgenden Indikators gelang es mir, cinen scharfen Farbenumschlag selbst bei $\mathrm{n} / 200-$ Sauren zu erreichen.

De r I 1 dikat or. Herstellung: I g alizarinsulfosaures Natrium wird in der Hitze in $100 \mathrm{ccm}$ Wasser gelöst und heiß in eine braune, gutschließende Tropfflasche filtriert. In einc zweite glcichartige Tropfflasche füllt man eine hciße Lösung von $0,05 \mathrm{~g}$ Methylenblau in $100 \mathrm{ccm}$ Wasser. Diese Flaschen sind stets gut verschlossen aufzubewahren, da die geringstc Menge Kohlcnsăure die Wirksamkeit des Indikators aufhebt. Auch dic Titrierlange darf kcin Karbonat enthalten. (Nic offen stehen lassen!)

$\mathrm{Z}_{11}$ dcr gekühlten Absorptionsflissigkeit setzt man nun 3 Tropfen alizarifisulfosaures Natrum und 6 Tropten Methylenblau hinzu. Man titriert aus einer schmalen Bürette. Der Umschlag erfolgt von braungrun ill violett und ist so deutlich, daß er ohne besondere Uebung wahrgenommen wird. Oft ist die Tropfengröße der beiden Flaschen nicht gleich. Man wird dann durch ein, zwei Versuche leicht das richtige Vcrhailtnis der beiden Tropfenzahlen zur. Erlangung des gewünschten Umschlages feststellen können. Am sichersten ist es wenn man mittels Pipetten $0,25 \mathrm{~cm}$ alizarinsulfosaures Natrium und 0,5 ccnı Methylenblau zusetzt. In Räumen, in denen mit Kohlensaure gearbeitet wurde, wird der Umschlag unscharf.

Berechnung. Die gefundenc Anzahl cem Natronlauge wird von 10 abgezogen, die Differenz mit $0,28 \mathrm{mg}$ multipliziert. Man crhält so die Milligramme Stickstoff in $1 \mathrm{ccm}$ Serum. Diese Zahl mit 100 multipliziert, ergibt den gebräuchlichen Wertausdruck für Reststickstoff.

Z B. verhraucht: $7,8 \mathrm{~cm} \mathrm{Na}$ OH

$$
\begin{aligned}
& 10-7,8=2,2 \\
& 2,2 \times 0,28=0,616 \\
& 0.646 \times 100=61,6 \\
& \text { Reststickstoff ist gleich } 61,6 .
\end{aligned}
$$

Falls die Reagenzien nicht ganz stickstofffrei sind, muß durch einen Blindversuch, zu dem man statt des Scrums $1 \mathrm{ccm}$ Wasser nimmt festgestellt werdcı, wieviel vorgelegte Säure vom Stickstoff der Rcagenzien verbraucht wird. Dicse Zahl zieht man dann jedesmal von den gefundenen Werten ab.

Das angegebene Veriahren eiguct sich naturlich auch zu jeder anderen Stickstoffbestimmung und ist besonders auch als Makroverfahren mit großem Vorteil zu verwenden. Bei Stickstofibestimmungen im Urin z. B. verwendet man $1 \mathrm{ccm}$ Urin, legt statt $\mathrm{dcr}$ n/100-Säure n/10-Säure vor und titriert unter Verwendung cines geWóknlichen Indikators mit $\mathrm{n} / 10$ Alkali.

Bei den hier wiedergegebenen Arbeiten wurde ich von Fräulcin Flisabeth Kootz in dankenswerter Weise unterstützt.

1) Der zusammengestellte Apparat wird gieichfalls von Franz Hugershoff in Leipzig geliefert. 